\title{
Absorption of iron by gastrectomized rats
}

\author{
J. S. W. WHITEHEAD AND R. M. BANNERMAN \\ with the technical assistance of J. HALFACREE
}

From the Nuffield Department of Surgery and the Nuffield Department of Medicine, Radcliffe Infirmary, Oxford

EDITORIAL SYNOPSIS Iron-deficiency anaemia develops after total gastrectomy in rats and responds well to iron given orally or by intramuscular injection. From these studies with ${ }^{59} \mathrm{Fe}$-tagged inorganic iron it is concluded that the anaemia is due to a quantitative defect in iron absorption while iron excretion is continuing at a normal or possibly at an increased rate.

Hypochromic anaemia is a common sequel of partial gastrectomy in man (Baird, Blackburn, and Wilson, 1959). In the rat, total gastrectomy, although not a strictly comparable operation, causes hypochromic anaemia and retarded growth, and death usually occurs within six to 12 months. Administration of iron corrects the anaemia, and may lead to increase in weight and prolongation of life (Bussabarger and Jung, 1936; Balfour, Higgins, and Woods, 1950; Johnston, Nevin, and Welbourn, 1960; Sheikh, 1960).

The purpose of the experiments reported here was to investigate by modern radioactive iron techniques the pathogenesis of this anaemia.

\section{MATERIALS AND METHODS}

Male Wistar albino rats weighing 250 to $500 \mathrm{~g}$. were fed on a commercial rat cake (M.R.C. 41B; Bruce and Parkes, 1949; Bruce, 1950). Twenty-one were operated on by one of us (J.S.W.W.) and their absorption of iron was tested between 11 and 380 days after operation. Seven had been operated on previously and were tested 420 to 550 days after operation. Twenty normal male rats of approximately the same age and weight were used as controls. Most animals were tested on more than one occasion.

TOTAL GASTRECTOMY Food, but not water, was withheld from the evening before operation. The animal was made drowsy in a jar of ether vapour, and full anaesthesia was induced by the intraperitoneal injection of pentobarbitone ( $2.7 \mathrm{mg}$. per $\mathrm{kg}$.) and maintained by open ether. The abdomen was opened in the midline from the xiphoid to $1 \frac{1}{2}$ in. below. The stomach was delivered and its blood vessels divided between ligatures. A curved artery forceps was put on the cardiac end of the stomach and the oesophagus cut above it. A stitch of 0000 silk was put in each side of the open oesophagus, which was drawn out of the wound. The duodenum was divided just distal to the pylorus. End-to-end oesophago-duodenal anastomosis was performed with one layer of continuous suture. The closure was completed over a rubber catheter passed through the mouth into the duodenum. The abdominal wall was repaired with two continuous silk sutures.

Penicillin, 100,000 units, and streptomycin, $0 \cdot 1$ g., were given subcutaneously and repeated the following day. Normal saline $(10 \mathrm{ml}$.) was injected subcutaneously, and water was withheld until the morning after operation. Solid food was provided 48 hours post-operatively.

WEIGHT, HAEMOGLOBIN AND MEAN CORPUSCULAR HAEMOGLOBIN CONCENTRATION Gastrectomized animals and controls were weighed at convenient intervals, and before and after each absorption test. Haemoglobin was estimated as oxyhaemoglobin by colorimetry, and packed cell volume by a micro-method, the blood being obtained by incision of a tail vein (McCall, Newman, O'Brien, Valberg, and Witts, 1962). The mean corpuscular haemoglobin concentration (M.C.H.C.) was calculated from the haemoglobin and haematocrit values.

IRON ABSORPTION TESTS The methods used in measuring the absorption in rats of iron tagged with ${ }^{59} \mathrm{Fe}$ have been described previously (Bannerman, O'Brien, and Witts, 1962). Inorganic iron was administered as ferrous ammonium sulphate at two dose levels (50 and $63 \mu \mathrm{g}$. Fe), each dose being labelled with approximately $0.25 \mu \mathrm{c}$ ${ }^{59} \mathrm{Fe}$ and given in a volume of $2 \mathrm{ml}$. of solution of $p \mathrm{H} 2$. Organic iron was given as haemoglobin tagged with ${ }^{59} \mathrm{Fe}$ in a standard dose containing the equivalent of $50 \mu \mathrm{g}$. $\mathrm{Fe}$ in $2 \mathrm{ml}$. It was prepared as a haemolysate of the washed red cells of a rabbit to which ${ }^{59} \mathrm{Fe}$ had been given intravenously more than four days before blood was withdrawn (Callender, Mallett, and Smith, 1957).

For the test, food was withheld from the animal for four hours and the dose was administered by a soft rubber catheter passed into the region of the anastomosis or the stomach with the animal under light ether anaesthesia. The rat was then put in a metabolic cage and food was replaced one hour later. Faeces were collected for 12 days, the period chosen in previous studies, to allow for delayed elimination noted previously in anaemic irondeficient rats (Bannerman et al., 1962). This is probably an unnecessarily long collection period but would not affect the results obtained. 
The percentage of each dose absorbed was determined by measuring the amount of radioactivity eliminated in the faeces in the 12-day collection and subtracting this from the total amount administered. The radioactivity of the whole collection was measured directly in a large phosphor well counter (Warner and Oliver, 1962), and as a check on accuracy, whole-body counting of retained radioactivity was also carried out in each animal on the twelfth day in the same counter. The values reported are those obtained by counting the faecal collections, but for inorganic iron results by the two methods have agreed to within $3 \%$. When repeated ${ }^{59} \mathrm{Fe}$ absorption tests were made on the same animals corrections were applied for radioactivity retained from previous doses.

OCCULT BLOOD TESTS A benzidine test was used; hydrogen peroxide ( $20 \mathrm{vol}$.) was added to an equal quantity of glacial acetic acid in which a small amount of benzidine was dissolved (Bayliss, 1950). Thin smears from the inside of the faecal pellet, moistened if necessary, were made on filter paper, and the mixture poured over them. The rapid appearance of a blue colour was regarded as a positive result, and if this was obtained, the faecal sample was mixed with water and boiled to eliminate 'false positives' caused by peroxidases, and the test repeated.

IRON TREATMENT Five anaemic gastrectomized rats were given a single dose of $10 \mathrm{mg}$. iron as iron-dextran $(0.2 \mathrm{ml}$. Imferon). Six were treated by substituting a $1 \%$ solution of ferrous sulphate for their drinking water for three weeks.

\section{RESULTS}

The animals lost weight rapidly in the first two weeks after total gastrectomy. In the following weeks this weight was only partially regained and thereafter there was little change in weight, in contrast to the control male rats, which continued to gain weight (Fig. 1).

Anaemia, as indicated by a haemoglobin level of less than $14 \mathrm{~g}$. per $100 \mathrm{ml}$, occurred in all 21 gastrectomized rats. Haemoglobin tended to fall progressively with increasing time after operation (Fig. 2). The anaemia was usually hypochromic (M.C.H.C. $32 \%$ or less) and responded to iron treatment. Figure 3 shows the effect of a course of oral ferrous sulphate or a single iron-dextran injection on haemoglobin level and body weight. The anaemia tended to recur when treatment was stopped.

Eleven of the gastrectomized rats died during this investigation. Six died of pneumonia or lung abscess approximately five months after operation when their average haemoglobin concentration was $8.1 \mathrm{~g} . / 100$ $\mathrm{ml}$. One of these rats died after its haemoglobin had been raised from $2.2 \mathrm{~g}$. $/ 100 \mathrm{ml}$. to $9.9 \mathrm{~g}$. $/ 100 \mathrm{ml}$. by an intramuscular injection of iron. Four died at three weeks and at four, five, and six months respectively, and the cause was not found at necropsy;

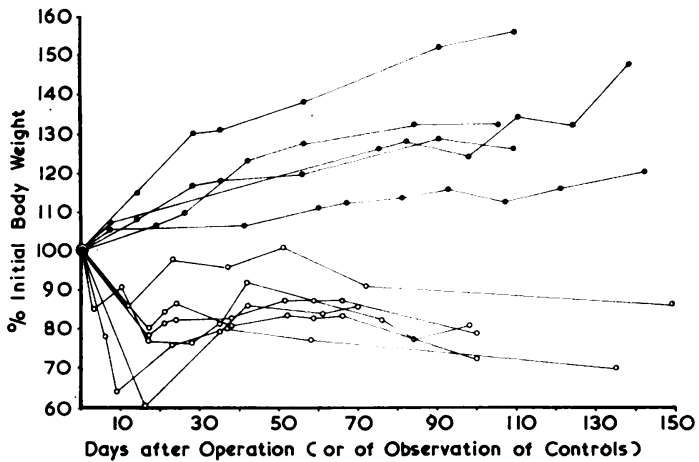

FIG. 1. Body weights of male rats following total gastrectomy $(\mathrm{O}-\mathrm{O})$ and before treatment with iron, expressed as percentages of the weight immediately before operation (250-500 g.), and of control male rats (-๑) over the same period, also expressed as percentages of their initial weights $(250-400 \mathrm{~g}$.).

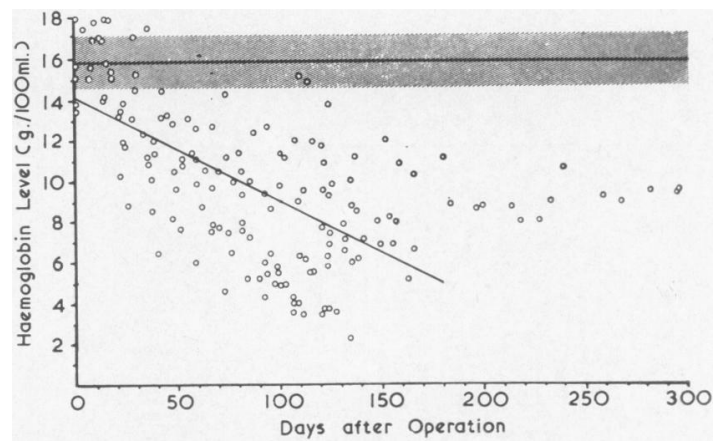

FIG. 2. Haemoglobin levels (0) in male rats following total gastrectomy compared with the mean value for control male rats on the same diet, represented by the shaded horizontal band for the mean $(15.9 \mathrm{~g} . / 100 \mathrm{ml}$.) \pm 1 standard deviation. The linear regression line for haemoglobin level $(y)$ against days after operation $(x)$ up to 180 days is shown; however, the relationship is probably curvilinear.

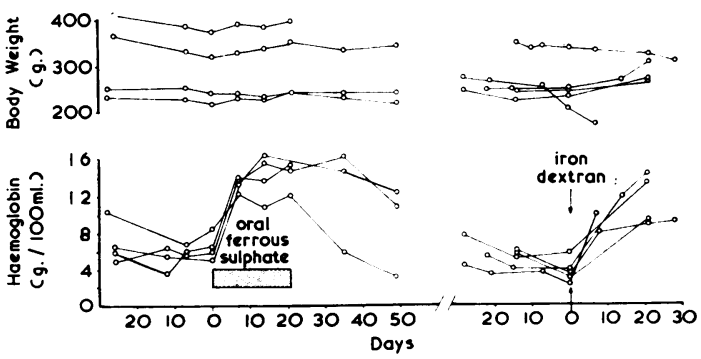

FIG. 3. Changes in body weights and haemoglobin levels of totally gastrectomized rats treated with iron (left) as oral ferrous sulphate solution (1\%) for three weeks, and (right) by a single intramuscular injection of iron-dextran (Imferon; $10 \mathrm{mg}$. Fe). 
the average haemoglobin of these four was $12 \cdot 4$ g. $/ 100 \mathrm{ml}$. One rat died in the fifth month while being dosed, and was presumed to have inhaled the fluid into its lungs after regurgitation.

The absorption of $50 \mu \mathrm{g}$. of inorganic iron was tested 19 times in gastrectomized rats and 10 times in controls (Table I). The mean level of absorption was not significantly different in the two groups (mean values $18.4 \%$ and $22.3 \%$ respectively), despite the fact that most of the gastrectomized rats were anaemic at the time of testing. It is interesting, however, that when individual gastrectomized rats are considered, the most anaemic animals did tend to absorb a higher percentage of the dose. Furthermore, in repeated tests on individual rats at different times absorption was greater when the haemoglobin level was lower.

Percentage absorption of the larger (63 $\mu \mathrm{g}$.) dose of inorganic iron was lower, as demonstrated previously (Bannerman et al., 1962) but there was again no significant difference between the mean values for the gastrectomized and control groups (Table I). Similar results were obtained in larger and older male rats gastrectomized more than 14 months previously, when compared with control rats of the same age (Table II).

Absorption of $50 \mu \mathrm{g}$. of tagged inorganic iron was very low in the rats whose anaemia had been treated by oral administration of ferrous sulphate (Table III).

The absorption of $50 \mu \mathrm{g}$. iron given as haemoglobin labelled with ${ }^{59} \mathrm{Fe}$ was tested 17 times in gastrectomized rats and 12 times in controls (Table IV). Neither group on average showed any significant absorption, though it is possible that very small amounts may have been retained.

TABLE I

ABSORPTION OF INORGANIC IRON BY INDIVIDUAL GASTRECTOMIZED RATS AT VARYING INTERVALS AFTER OPERATION

\begin{tabular}{|c|c|c|c|c|c|}
\hline Rat No. & Days Post-operatively & Weight (g.) & $\mathrm{Hb}(\mathrm{g} . / 100 \mathrm{ml})$. & M.C.H.C. & $\%$ Absorbed \\
\hline \multicolumn{6}{|c|}{ Dose of $50 \mu \mathrm{g} . \mathrm{Fe}^{2}$} \\
\hline 882 & 11 & 232 & $16 \cdot 0$ & 41 & 6.5 \\
\hline 840 & 16 & - & - & - & $25 \cdot 8$ \\
\hline 838 & 20 & - & - & - & 14.5 \\
\hline 873 & 21 & 171 & $18 \cdot 1$ & 38 & 0.3 \\
\hline 891 & 24 & 407 & $13 \cdot 1$ & 33 & $15 \cdot 6$ \\
\hline 893 & 24 & 428 & $11 \cdot 7$ & 32 & $12 \cdot 4$ \\
\hline 877 & 25 & 253 & $10 \cdot 3$ & 30 & $13 \cdot 0$ \\
\hline 888 & 35 & 295 & $10 \cdot 8$ & 35 & $17 \cdot 0$ \\
\hline 805 & 51 & 341 & 8.5 & 36 & $20 \cdot 2$ \\
\hline 824 & 53 & 280 & 10.5 & 30 & $18 \cdot 7$ \\
\hline 826 & 53 & 367 & 12.9 & 30 & 17.9 \\
\hline 803 & 54 & 366 & 7.8 & 39 & $21 \cdot 7$ \\
\hline 811 & 60 & 315 & $13 \cdot 1$ & 29 & 8.7 \\
\hline 873 & 70 & 243 & $7 \cdot 7$ & 28 & $20 \cdot 0$ \\
\hline 861 & 73 & 399 & $13 \cdot 3$ & 33 & $21 \cdot 6$ \\
\hline 826 & 135 & 359 & 10.0 & 30 & $43 \cdot 7$ \\
\hline 811 & 142 & 306 & $10 \cdot 2$ & 29 & 5.7 \\
\hline 861 & 175 & 398 & 8.8 & 32 & $40 \cdot 0$ \\
\hline 861 & 205 & 410 & $8 \cdot 6$ & 27 & $21 \cdot 2$ \\
\hline 840 & 252 & 390 & 8.9 & 32 & $16 \cdot 3$ \\
\hline 840 & 285 & 402 & $9 \cdot 4$ & 32 & $26 \cdot 0$ \\
\hline \multirow{2}{*}{\multicolumn{2}{|c|}{$\begin{array}{l}\text { Mean } \pm \text { S.D. } \\
\text { Mean } \pm \text { S.D. for } 10 \text { controls }\end{array}$}} & $337 \pm 24$ & $11 \cdot 0 \pm 2.0$ & $32 \pm 3 \cdot 6$ & $18 \cdot 4 \pm 10 \cdot 18$ \\
\hline & & $314 \pm 29$ & $16 \cdot 0 \pm 0 \cdot 3$ & $34 \pm 2 \cdot 2$ & $22 \cdot 3 \pm 2 \cdot 6$ \\
\hline \multicolumn{6}{|c|}{ Dose of $63 \mu \mathrm{g} . \mathrm{Fe}^{2}$} \\
\hline 824 & 32 & 298 & $15 \cdot 3$ & 36 & 5.6 \\
\hline 826 & 32 & 318 & 14.5 & 35 & 20.9 \\
\hline 811 & 39 & 290 & $14 \cdot 2$ & 36 & 14.5 \\
\hline 894 & 63 & 261 & 11.4 & 30 & $13 \cdot 3$ \\
\hline 891 & 84 & 393 & 7.7 & 36 & 14.6 \\
\hline 893 & 84 & 453 & $9 \cdot 3$ & 31 & 33.5 \\
\hline 888 & 95 & 317 & 9.4 & 29 & 15.2 \\
\hline 857 & 105 & 292 & 6.9 & 26 & 30.2 \\
\hline 858 & 105 & 266 & $9 \cdot 3$ & 25 & $21 \cdot 4$ \\
\hline 861 & 105 & 316 & $11 \cdot 1$ & 31 & $20 \cdot 1$ \\
\hline 825 & 116 & 321 & 8.8 & 31 & $10 \cdot 7$ \\
\hline 840 & 170 & 367 & 12.0 & 31 & 15.0 \\
\hline 853 & 140 & 256 & 3.6 & 21 & 6.1 \\
\hline 838 & 144 & 250 & 6.9 & 25 & $13 \cdot 4$ \\
\hline 825 & 158 & 298 & 9.9 & 29 & $12 \cdot 1$ \\
\hline 840 & 182 & 387 & $11 \cdot 1$ & 31 & 1.5 \\
\hline \multicolumn{2}{|c|}{$\begin{array}{l}\text { Mean } \pm \text { S.D. } \\
\text { Mean } \pm \text { S.D. for four controls }\end{array}$} & $\begin{array}{l}318 \pm 55 \\
340 \pm 52\end{array}$ & $\begin{array}{l}10.1 \pm 1.6 \\
16.9 \pm 1.0\end{array}$ & $\begin{array}{l}30 \pm 4 \cdot 4 \\
37 \pm 1 \cdot 5\end{array}$ & $\begin{array}{l}15 \cdot 5 \pm 1 \cdot 5 \\
11 \cdot 7 \pm 13 \cdot 3\end{array}$ \\
\hline
\end{tabular}


TABLE II

ABSORPTION OF INORGANIC IRON $\left(50 \mu \mathrm{g}\right.$. $\left.\mathrm{Fe}^{2}\right)$ BY INDIVIDUAL GASTRECTOMIZED RATS AT LONGER INTERVALS AFTER OPERATION

\begin{tabular}{|c|c|c|c|c|c|}
\hline Rat No. & Days Post-operatively & Weight (g.) & $\mathrm{Hb}(\mathrm{g} . / 100 \mathrm{ml})$. & M.C.H.C. & $\%$ Absorbed \\
\hline 4 & 420 & 400 & $12 \cdot 3$ & - & $17 \cdot 0$ \\
\hline 78 & 420 & 381 & 15.7 & - & $10 \cdot 6$ \\
\hline 4 & 510 & 407 & 8.2 & 29 & 12.0 \\
\hline 5 & 510 & 473 & $11 \cdot 1$ & 33 & 15.0 \\
\hline 127 & 510 & 390 & 16.9 & 37 & 14.0 \\
\hline 128 & 510 & 363 & $8 \cdot 4$ & - & 16.0 \\
\hline 4 & 550 & 420 & 9.0 & - & 12.0 \\
\hline 5 & 550 & 467 & 12.9 & 31 & 12.0 \\
\hline 98 & 550 & 395 & 9.0 & 29 & $33 \cdot 0$ \\
\hline 127 & 550 & 380 & $17 \cdot 3$ & 34 & 10.0 \\
\hline 128 & 550 & 333 & $4 \cdot 8$ & 25 & $18 \cdot 0$ \\
\hline \multicolumn{2}{|c|}{$\begin{array}{l}\text { Mean } \pm \text { s.d. ( } 10 \text { gastrectomized) } \\
\text { Mean } \pm \text { s.d. (six controls of same age) }\end{array}$} & $\begin{array}{l}401 \pm 41 \cdot 2 \\
482 \pm 12.6\end{array}$ & \multicolumn{2}{|l|}{$\begin{array}{l}11.4 \pm 4.0 \\
16.8 \pm 0.7\end{array}$} & $\begin{array}{l}15.4 \pm 6.6 \\
13.6 \pm 4.2\end{array}$ \\
\hline
\end{tabular}

TABLE III

ABSORPTION OF $50 \mu \mathrm{g}$ INORGANIC IRON BY GASTRECTOMIZED RATS SOME WEEKS BEFORE AND AFTER TREATMENT WITH ORAL FERROUS SULPHATE

\begin{tabular}{|c|c|c|c|c|c|}
\hline \multirow[t]{2}{*}{ Rat No. } & \multicolumn{2}{|l|}{ Before Treatment } & \multicolumn{2}{|l|}{ After Treatment } & \multirow{2}{*}{$\begin{array}{l}\text { Weeks after } \\
\text { Ending Treatment }\end{array}$} \\
\hline & $H b(g . / 100 \mathrm{ml})$. & $\%$ Absorbed & $H b(g . / 100 \mathrm{ml})$. & $\%$ Absorbed & \\
\hline 877 & $10 \cdot 3$ & $13 \cdot 0$ & $12 \cdot 0$ & $4 \cdot 8$ & 1 \\
\hline 891 & $13 \cdot 1$ & $15 \cdot 6$ & $14 \cdot 6$ & $7 \cdot 0$ & 1 \\
\hline 891 & - & - & $10 \cdot 8$ & $9 \cdot 9$ & 4 \\
\hline 894 & $11 \cdot 4$ & $13 \cdot 3$ & $10 \cdot 3$ & 0.0 & 1 \\
\hline 894 & - & - & $12 \cdot 3$ & $6 \cdot 8$ & 4 \\
\hline
\end{tabular}

TABLE IV

TESTS OF ABSORPTION OF HAEMOGLOBIN IRON $(50 \mu \mathrm{g}$. Fe) BY GASTRECTOMIZED AND CONTROL MALE RATS

\begin{tabular}{|c|c|c|c|c|c|}
\hline Rat No. & Days Post-operatively & Weight $(g)$. & $H b(g . / 100 \mathrm{ml})$. & M.C.H.C. & $\begin{array}{l}\text { Percentage of Administered Dose } \\
\text { Eliminated in Faeces }\end{array}$ \\
\hline \multicolumn{6}{|c|}{ Gastrectomized rats } \\
\hline 842 & 7 & 177 & $16 \cdot 0$ & 31 & $99 \cdot 4$ \\
\hline 805 & 18 & 271 & $17 \cdot 9$ & 34 & $102 \cdot 2$ \\
\hline 803 & 21 & 355 & $12 \cdot 0$ & 32 & $111 \cdot 2$ \\
\hline 873 & 42 & 231 & $13 \cdot 2$ & 29 & $99 \cdot 8$ \\
\hline 826 & 74 & 397 & $13 \cdot 9$ & 33 & 97.6 \\
\hline 811 & 80 & 313 & $11 \cdot 2$ & 31 & $106 \cdot 7$ \\
\hline 888 & 129 & 285 & $8 \cdot 5$ & 24 & 103.9 \\
\hline 861 & 147 & 365 & $8 \cdot 0$ & 31 & $105 \cdot 3$ \\
\hline 803 & 147 & 313 & 6.9 & - & $92 \cdot 4$ \\
\hline 805 & 150 & 296 & 6.0 & 31 & $104 \cdot 2$ \\
\hline 873 & 196 & 273 & $10 \cdot 8$ & 30 & $107 \cdot 5$ \\
\hline 840 & 224 & 387 & $10 \cdot 6$ & 31 & $109 \cdot 9$ \\
\hline 824 & 228 & 327 & $8 \cdot 7$ & 26 & 99.4 \\
\hline 811 & 229 & 391 & $7 \cdot 5$ & 28 & $100 \cdot 4$ \\
\hline 894 & 159 & 207 & $7 \cdot 1$ & 25 & $100 \cdot 7$ \\
\hline \multicolumn{2}{|c|}{ Mean \pm s.d. } & $319 \pm 79$ & $10.7 \pm 5.8$ & $30 \pm 2 \cdot 8$ & $102.4 \pm 1.6$ \\
\hline \multicolumn{6}{|c|}{ Control rats } \\
\hline 817 & - & 434 & $16 \cdot 0$ & 33 & $106 \cdot 0$ \\
\hline 818 & - & 349 & $16 \cdot 0$ & 33 & $89 \cdot 7$ \\
\hline 800 & - & 250 & $19 \cdot 1$ & 35 & 91.0 \\
\hline 801 & - & 279 & 16.9 & 35 & $92 \cdot 7$ \\
\hline 800 & - & 378 & $16 \cdot 6$ & 38 & $104 \cdot 4$ \\
\hline 801 & - & 427 & $16 \cdot 8$ & 37 & 103.0 \\
\hline 808 & - & 486 & $16 \cdot 0$ & 36 & $100 \cdot 5$ \\
\hline 816 & - & 397 & $17 \cdot 5$ & 36 & $102 \cdot 2$ \\
\hline 901 & - & - & - & - & $100 \cdot 0$ \\
\hline 902 & - & - & - & - & 103.0 \\
\hline 903 & - & - & - & - & 99.0 \\
\hline 904 & - & - & - & - & $101 \cdot 0$ \\
\hline \multicolumn{2}{|c|}{ Mean \pm s.d. } & $375 \pm 67$ & $16.9 \pm 1.9$ & $35 \pm 4 \cdot 1$ & $99.4 \pm 1.6$ \\
\hline
\end{tabular}


Repeated tests were made for occult blood in the faeces of 11 control and 13 gastrectomized rats. Positive results were always obtained in the first post-operative week. Subsequent tests were only rarely positive and the faeces of four gastrectomized rats, tested serially at intervals of three to seven days for four months, gave negative results at all times. These four rats nevertheless became severely anaemic (haemoglobin levels $3 \cdot 0,3 \cdot 4,3 \cdot 5$, and $6 \cdot 6 \mathrm{~g} . / 100 \mathrm{ml}$.) during this time. One rat was repeatedly found to have occult blood in its faeces approximately five months after operation but its haemoglobin concentration had only fallen to $10 \cdot 8 \mathrm{~g}$. $/ 100 \mathrm{ml}$. Only one positive reaction was obtained in $\mathbf{4 0}$ serial tests on the faeces of 11 control rats.

\section{DISCUSSION}

Severe iron-deficiency anaemia is a striking feature of the totally gastrectomized rat and one purpose of this investigation was to determine how the anaemia develops. It appears quite rapidly; within three months of operation the haemoglobin level of most of the animals had fallen below $11 \mathrm{~g}$. per $100 \mathrm{ml}$. (Fig. 2). During this time the average daily loss of iron must have regularly exceeded the daily intake so that stores were depleted and anaemia developed.

Although there is not enough information to draw up an exact balance sheet for iron, the quantitative aspects of its turnover must be considered. At the time of operation the rats were not anaemic and indeed are likely to have had iron stores amounting to several milligrams (Spray and Widdowson, 1950; Bannerman, O'Brien, Williams, and Witts, 1963). There was no increased demand for iron due to growth since growth ceased after operation (Fig. 1). The anaemia must therefore be due to a decrease in iron absorption or to an increase in the rate of loss of iron, or both.

The rats' diet contained $95 \mathrm{mg}$. Fe/kg. (McCall et al., 1962), an iron content considered more than adequate for all needs in normal rats. The greater part of the iron in the cake diet is added as hydrated iron oxides (Elstub, personal communication, 1962). The normal level of iron absorption from such a diet is unknown, but from other data on food-iron absorption (Callender, 1959) it might be speculated that $10 \%$ would be absorbed. Thus, if a normal rat consumed $10 \mathrm{~g}$. of diet per day it would absorb $100 \mu \mathrm{g}$. Fe.

In our measurements of iron absorption using ${ }^{59} \mathrm{Fe}$ no difference could be demonstrated between gastrectomized and control rats in their ability to absorb iron. At first sight this might seem to indicate that gastrectomy had no effect on iron absorption but it must be emphasized that many of the gastrec- tomized animals were severely iron-deficient at the time of testing, whereas the control animals were not anaemic and had adequate iron stores. It is well known that iron deficiency enhances iron absorption. For example, young rats made iron-deficient by diet absorb $82.7 \%$ of a $50 \mu \mathrm{g}$. dose of ferrous iron while their litter mates on a high iron diet absorb only $7.9 \%$ (Bannerman et al., 1962). Both these groups of young rats absorb the iron of haemoglobin effectively and the iron-deficient rats absorb more (Bannerman, R. M., unpublished observations, 1962). The control rats in the present experiments were older, had almost ceased growing, and had adequate iron stores so that it is not surprising that they failed to show any appreciable absorption of haemoglobin iron. It is, however, remarkable that the anaemic gastrectomized animals failed to do so.

Gastrectomy seems therefore to have removed the animal's capacity to increase its absorption of iron in response to iron deficiency whether the iron was given in inorganic form or as haemoglobin. The defect is thus quantitative and not absolute, and it is one which can be overcome by giving a sufficiently large dose, as shown by the effect of $1 \%$ ferrous sulphate solution in curing the anaemia. It is very likely that this defect would apply also to day-to-day absorption of the iron compounds in the cake diet.

The exact mechanism of the defect is not clear but it may be speculated that one factor is the rapid transit of food through the upper small intestine. The total transit time, as indicated by the rate of appearance in the faeces of the unabsorbed portion of a dose of ${ }^{59} \mathrm{Fe}$, is, however, the same in gastrectomized animals as in controls (Bannerman, R. M., unpublished observations, 1960). The duodenum, the main site of iron absorption, is not bypassed, and the absence of gastric secretions, including acid, is probably less important, since they are not now believed to have a vital role in iron absorption (Biggs, Bannerman, and Callender, 1962).

Impairment of absorption can scarcely account by itself for the appearance of iron-deficiency anaemia, unless the losses of iron are increased. Blood loss at and immediately after operation accounts for some, but scarcely for the progressive and recurrent development of iron deficiency. Although occult bleeding due to oesophagitis (Helsingen, 1960) might be suspected as a cause it was detected only very rarely after the first post-operative week.

Recent studies on iron excretion in the rat (Bannerman, O'Brien, Williams, and Witts, 1963) suggest that an animal weighing $300 \mathrm{~g}$. and eating a diet adequate in iron might excrete in the faeces approximately $100 \mu \mathrm{g}$. Fe daily in addition to that not absorbed from the food. Over one month this would account for $3 \mathrm{mg}$., even if, as has been shown, it is 
reduced in iron deficiency. It is likely that the faecal excretion represents less than the total amount of iron excreted into the gastro-intestinal lumen, some of which is probably reabsorbed. Thus it is possible that such normal conservation might be disturbed after total gastrectomy and indeed it is difficult not to conclude that iron excretion is in some way accelerated.

It is of interest to compare these results with the effect of total gastrectomy in man. In the rat, the completely peritonealized duodenum permits direct oesophago-duodenostomy, whereas the techniques usually employed in man exclude the duodenum from the direct pathway of food. The operation is usually performed for carcinoma of the stomach or lower oesophagus and the patients frequently succumb to recurrence of the carcinoma. It is more rarely employed in treating benign conditions (Roxburgh, 1962), and patients may then become available for more prolonged study. However, when the human subject is deprived by total gastrectomy of ability to secrete intrinsic factor, megaloblastic anaemia due to vitamin $\mathbf{B}_{12}$ deficiency always develops if he survives sufficiently long and iron-deficiency anaemia may occur also (Blake and Rechnitzer, 1953). Similar effects may also result from complete bypassing of the stomach by operation in man (Callender, Witts, Allison, and Gunning, 1961). In contrast, although gastrectomized rats show defective absorption of vitamin $B_{12}$, which can be corrected by the administration of intrinsic factor (Watson and Florey, 1955; Taylor, Mallet, Witts, and Taylor, 1958), and their serum and liver $B_{12}$ levels tend to fall (Booth and Spray, 1960, 1962), the anaemia which develops responds to iron alone, is not macrocytic, and megaloblastic changes do not occur in the bone marrow (Bussabarger and Jung, 1936), nor does megaloblastic anaemia appear when the iron deficiency is corrected.

Thus a more useful comparison may be with partial gastrectomy in man, an operation which is followed by an iron-deficiency anaemia in half the male and nearly all the female patients (Hobbs, 1961). This anaemia has been much investigated but its mechanism is still not clear. The role of increased iron loss is variable, since positive occult blood tests are found in only a small proportion of the patients (Smith and Mallet, 1957; Baird, Blackburn, and Wilson, 1959) and the rate of turnover of ${ }^{59} \mathrm{Fe}$ in the whole body apparently remains the same as normal (Stevens, Pirzio-Biroli, Harkins, Nyhus, and Finch, 1959). Smith and Mallett (1957) found that the capacity to absorb ferrous sulphate given fasting with ascorbic acid was unimpaired, which reflects the usual experience that the anaemia responds well to the administration of iron salts by mouth (Stevens et al., 1959).
Duthie (1959) could demonstrate no difference in the capacity to absorb iron after Billroth I or Polya gastrectomy. However, when tagged iron was given mixed with food (Baird, Podmore, and Wilson, 1957) or baked into bread (Choudhury and Williams, 1959) partially gastrectomized subjects absorbed less than controls or failed to show an increase in absorption when anaemic. It would appear that the defect in absorption is a quantitative one, as in the totally gastrectomized rats.

\section{SUMMARY AND CONCLUSIONS}

It is confirmed that total gastrectomy in rats halts growth and is rapidly followed by the development of severe iron-deficiency anaemia.

The anaemia responded well to iron given orally or by intramuscular injection but tended to recur when treatment was stopped.

The absorption of ${ }^{59} \mathrm{Fe}$-tagged inorganic iron by gastrectomized rats was on the average the same as that of normal controls, even though many of the gastrectomized rats were severely anaemic when tested. They failed to show an appropriate increase in iron-absorbing capacity with anaemia, though there was a slight tendency for the more anaemic animals to absorb more iron.

There was no significant absorption of iron of ${ }^{59} \mathrm{Fe}$-tagged haemoglobin by gastrectomized or control rats, though it is known that iron in this form is absorbed by younger growing rats and rats made iron-deficient by diet.

Occult bleeding did not account for the development of anaemia.

It is concluded that the anaemia of totally gastrectomized rats is due to a quantitative defect in iron absorption while iron excretion is continuing at a normal or possibly an increased rate.

We thank Professor L. J. Witts for providing the facilities for this work and for his valuable criticism of the manuscript. We are indebted to Dr. K. B. Taylor who taught one of us the technique of total gastrectomy in the rat and to Dr. M. Sheikh who kindly handed on to us animals surviving his previous investigations.

\section{REFERENCES}

Baird, I. McL., Blackburn, E. K., and Wilson, G. M. (1959). The pathogenesis of anaemia after partial gastrectomy. Quart. J. Med., 28, 21-41.

- Podmore, D. A., and Wilson, G. M. (1957). Changes in iron metabolism following gastrectomy and other surgical operations. Clin. Sci., 16, 463-473.

Balfour, D. C., Jr., Higgins, G. M., and Woods, K. A. (1950). A factor in neutralized human gastric juice which prolongs survival of gastrectomized rats. Proc. Mayo. Clin., 25, 434-441.

Bannerman, R. M., O'Brien, J. R. P., Williams, D. L. and Witts, L. J. (1963). Studies in iron metabolism V. Excretion of iron in the rat. In preparation. 
Bannerman, R. M., O'Brien, J. R. P., and Witts, L. J. (1962). Studies in iron metabolism. IV. Iron absorption in experimental iron deficiency. Blood, 20, 532-546.

Bayliss, R. I. S. (1950). Practical Procedures in Clinical Medicine, p. 49. Churchill, London.

Biggs, J. C., Bannerman, R. M., and Callender, S. T. (1962). Iron absorption in achlorhydria. Proc. 8th Congr. europ. Soc. Haematol. I, abstr., 236.

Blake, J., and Rechnitzer, P. A. (1953). The haematological and nutritional effects of gastric operations. Quart. J. Med., 22 419-437.

Booth, M. A., and Spray, G. H. (1960). Vitamin $B_{12}$ activity in the serum and liver of rats after total gastrectomy. Brit. J. Haemat. 6, 288-295.

- (1962). Effect of iron on the vitamin $\mathbf{B}_{12}$ activity in the serum and liver of totally gastrectomized rats. Ibid., 8, 110-113.

Bruce, H. M. (1950). Feeding and breeding of laboratory animals. XI. Vitamin E deficiency in mice on a diet containing $85 \%$ of whole-grain cereals, after the addition of $2 \%$ of cod-liver oil. J. Hyg. (Lond.), 48, 171-183.

— , and Parkes, A. S. (1949). Feeding and breeding of laboratory animals. IX. A complete cubed diet for mice and rats. J. Hyg. (Lond.), 47, 202-208.

Bussabarger, R. A., and Jung, F. T. (1936). Dietary and hematologic studies after gastrectomy in the rat. Amer. J. Physiol., 117, 59-67.

Callender, S. T. (1959). Iron absorption. Brit. Med. Bull., 15, 5-8.

, Mallett, B. J., and Smith, M. D. (1957). Absorption of haemoglobin iron. Brit. J. Haemat., 3, 186-192.

—, Witts, L. J., Allison, P. R., and Gunning, A. J. (1961). Some metabolic and haematological effects of oesophago-jejunostomy with by-pass of the stomach. Gut, 2, 150-156.

Choudhury, M. R., and Williams, J. (1959). Iron absorption and gastric operations. Clin. Sci., 18, 527-532.
Duthie, H. L. (1959). Absorption of inorganic iron after partial gastrectomy: comparison of the Polya and the Billroth I operations. Scot. med. J., 4, 523-526.

Helsingen, N., Jr. (1960). Oesophagitis following total gastrectomy in rats. II. Development of oesophagitis in relation to type of reconstruction. Acta. chir. scand., 119, 230-245.

Hobbs, J. R. (1961). Iron deficiency after partial gastrectomy. Gut, 2 , 141-149.

Johnston, I. D. A., Nevin, H. O., and Welbourn, R. B. (1960). The syndrome of nutritional deficiency after gastrectomy in the rat. Brit. J. Surg., 48, 81-86.

McCall, M. G., Newman, G. E., O'Brien, J. R. P., Valberg, L. S., and Witts, L. J. (1962). Studies in iron metabolism. I. The experimental production of iron deficiency in the growing rat. Brit $J$. Nutr., 16, 297-304.

Roxburgh, R. A. (1962). The case for total gastrectomy in multiple polyposis of the stomach. Gut, 3, 224-231.

Sheikh, M. A. (1960). The assay in the rat of preparations of intrinsic factor. Ph.D. Thesis, Oxford.

Smith, M. D., and Mallett, B. (1957). Iron absorption before and after partial gastrectomy. Clin. Sci., 16, 23-34.

Spray, C. M., and Widdowson, E. M. (1950). The effect of growth and development on the composition of mammals. Brit. J. Nutr., 4, 332-353.

Stevens, A. R., Jr., Pirzio-Biroli, G., Harkins, H. N., Nyhus, L. M., and Finch, C. A. (1959). Iron metabolism in patients after partial gastrectomy. Ann. Surg., 149, 534-538.

Taylor, K. B., Mallett, B. J., Witts, L. J., and Taylor, W. H. (1958). Observations on vitamin-B $B_{12}$ absorption in the rat. Brit. J. Haemat., 4, 63-69.

Warner, G. T., and Oliver, R. (1962). A plastic phosphor well counter for sample volumes up to $400 \mathrm{ml}$. Brit. J. Radiol., 35, 349-352.

Watson, G. M., and Florey, H. W. (1955). The absorption of vitamin $B_{12}$ in gastrectomised rats. Brit. J. exp. Path., 36, 479-486. 